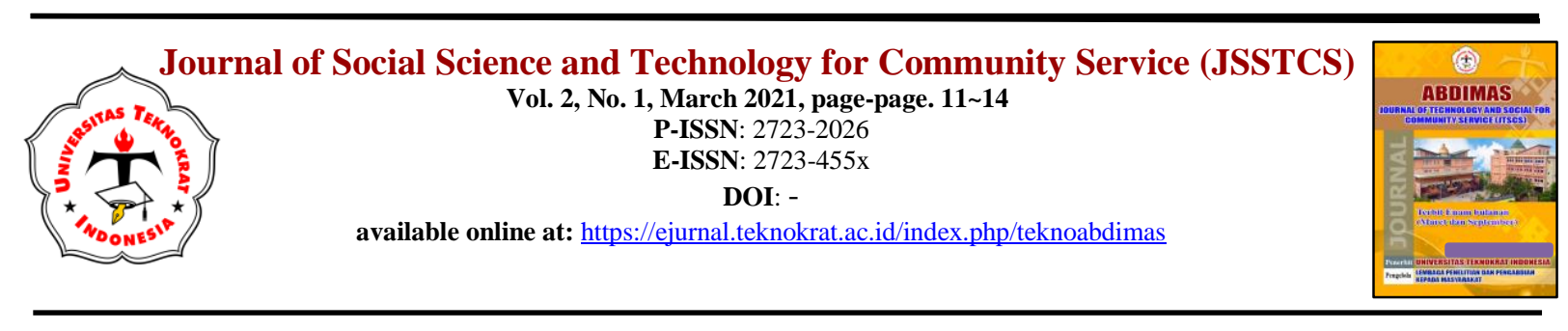

\title{
PELATIHAN PENANGANAN CIDERA OLAHRAGA DI SMA NEGERI 1 PRINGSEWU
}

\author{
Eko Bagus Fahrizqi ${ }^{1}$, Rachmi Marsheilla Aguss $^{2}$,Rizki Yuliandra ${ }^{3}$ \\ Universitas Teknokrat Indonesia, ${ }^{\mathbf{1 , 2 , 3}}$
}

Email :eko.bagus@teknokrat.ac.id ${ }^{1}$,rachmi.ma@teknokrat.ac.id ${ }^{2}$,rizki.yuliandra@teknokrat.ac.id ${ }^{3}$

\begin{tabular}{lll}
\hline Received: (30 Maret 2021) & Accepted: (30 Maret 2021) & Published : (30 Maret 2021)
\end{tabular}

\begin{abstract}
Sports activities with injuries, especially for sportsmen or athletes. For that we must be careful in exercising so as not to get injured. Before exercising or playing, try to warm up first, then after cooling down. To reduce the risk of injury. Sports injuries are defined as injuries that occur as a result of sports activities, either directly or indirectly, which affect the musculoskeletal system and all other systems or organs that affect it, causing malfunctioning of the system.

There are many extracurricular activities followed by students. Some students who attend school have athletic backgrounds. Apart from training activities at school there are also those who practice outside the school schedule. So that with the dense exercise schedule, it more or less affects the condition of the body. There are many sports injuries in the field that are not handled properly. Sports massage is a skill that is used to treat sports injuries. Therefore sports massage can be used as a therapeutic tool for both prevention, health and healing of diseases. This is because there are still many athletes who lack knowledge about handling sports injuries through sports massage. Based on the above facts, the service team feels the need to provide massage skills for students who take extracurricular sports at SMAN 1 Pringsewu.

The objectives of this community service are: (1) Provide knowledge and theory about massage for students who take sports extracurricular activities at SMAN 1 Pringsewu., (2) Provide massage skills for prevention, health, and healing for students who take extracurricular sports in SMAN 1 Pringsewu.
\end{abstract}

Keywords: Injuries, Sport, Massage

\begin{abstract}
Abstrak.
Kegiatan olahraga dengan cedera, terutama bagi para olahragawan atau atlet. Untuk itu kita harus berhati - hati dalam berolahraga agar tidak mengalami cedera. Sebelum berolahraga atau bermain usahakan melakukan pemanasan terlebih dahulu, kemudian setelah selesai melakukan pendinginan. Untuk mengurangi resiko terjadinya cedera. Cedera olahraga diartikan sebagai cedera yang terjadi akibat kegiatan olahraga baik secara langsung atau tidak langsung, yang mengenai sistem muskuloskeletal dan semua sistem atau organ lain yang memengaruhinya sehingga menimbulkan gangguan fungsi sistem tersebut.

Ekstrakurikuler yang ada banyak di ikuti oleh siswa. Beberapa siswa yang bersekolah ada yang berlatar belakang atlet. Selain kegiatan latihan disekolah ada juga yang berlatih diluar jadwal sekolah. Sehingga dengan padatnya jadwal latihan tersebut, kurang lebih mempengaruhi kondisi badan. Banyak nya cedera olahraga dilapangan yang tidak ditangani dengan benar. Sport massage merupakan sebuah keahlian yang digunakan sebagai penanganan cedera pada olahraga. Oleh karena itu sport massage dapat digunakan sebagai alat terapi baik untuk pencegahan, kesehatan, dan penyembuhan penyakit. Dikarenakan masih banyak atlet kurang pengetahuan tentang penanganan cedera olahraga melalui sport massage. Berdasarkan kenyataan di atas, tim pengabdi merasa perlu untuk memberikan keterampilan massage bagi siswa yang mengikuti ekstrakurikuler Olahraga di SMAN 1 Pringsewu.

Tujuan dari pengabdian pada masyarakat ini adalah: (1) Memberi bekal pengetahuan dan teori tentang massage bagi siswa yang mengikuti ekstrakurikuler Olahraga di SMAN 1 Pringsewu., (2) Membekali keterampilan massage untuk pencegahan, kesehatan, dan penyembuhan pada siswa yang mengikuti ekstrakurikuler Olahraga di SMAN 1 Pringsewu.
\end{abstract}

Kata Kunci: Cedera, Olahraga, Massage 
To cite this article:

Authors. (Year). Title of the article. Journal of Technology and Social for Community Service (JTSCS), Vol(1), Page-Page.

\section{PENDAHULUAN}

Kegiatan ekstrakurikuler atau ekskul adalah kegiatan tambahan yang dilakukan di luar jam pelajaran yang dilakukan baik di sekolah atau di luar sekolah dengan tujuan untuk mendapatkan tambahan pengetahuan, keterampilan dan wawasan serta membantu membentuk karakter peserta didik sesuai dengan minat dan bakat masing-masing. Berdasarkan Surat Keputusan Menteri Pendidikan dan Kebudayaan No. 060/U/1993 dan Nomor 080/U/1993, kegiatan ekstrakurikuler adalah kegiatan yang diselenggarakan di luar jam pelajaran yang tercantum dalam susunan program sesuai dengan keadaan dan kebutuhan sekolah, dan dirancang secara khusus agar sesuai dengan faktor minat dan bakat siswa.

Di setiap sekolah pasti mempunyai berbagi macam kegiatan ekstrakurikuler baik yang bersifat akademik maupun non- Akademik. Menurut Permendikbud No. 81A Tahun 2013, terdapat beberapa jenis kegiatan ekstrakurikuler, yakni Krida, yang melingkupi bidang Kepramukaan, Latihan Dasar Kepemimpinan Siswa, Palang Merah Remaja (PMR), Pasukan Pengibar Bendera (Paskibra) dan lainnya. Karya ilmiah, yang melingkupidi bidang Kegiatan Ilmiah Remaja (KIR), Kegiatan Penguasaan Keilmuan dan kemampuan akademik, penelitian dan sebagainya. Latihan/olah bakat/prestasi, yang melingkupi dibidang Pengembangan bakat olahraga, seni dan budaya, cinta alam, jurnalistik, teater, keagamaan, dan lainnya.

Dalam lingkungan Sekolah SMAN 1 Pringsewu, kegiatan ekstrakurikuler menjadi kegiatan tambahan yang harus diikuti oleh siswa. Kegiatan ekstrakurikuler dijalankan setelah pulang sekolah atau jam diluar kegiatan aktif sekolah. SMAN 1 Pringsewu banyak memiliki kegiatan ekstrakurikuler merujuk dari peraturan pemerintah yang ada. ekstrakurikuler yang ada antara lain,KIR, PMR, Pramuka, ROHIS, Basket, Futsal, Taekwondo, Karate, Sepakbola dan lainnya. Ekstrakurikuler yang paling diminati adalah eksul olahraga. Kegiatan ekstrakurikuler olahraga memiliki latihan yang berbeda disetiap cabangnya. Olahraga dekat kaitannya dengan cedera, terutama bagi para olahragawan atau atliet. Untuk itu kita harus berhati - hati dalam berolahraga agar tidak mengalami cedera. Sebelum berolahraga atau bermain usahakan melakukan pemanasan terlebih dahulu, kemudian setelah selesai melakukan pendinginan. Untuk mengurangi resiko terjadinya cedera. Cedera olahraga diartikan sebagai cedera yang terjadi akibat kegiatan olahraga baik secara langsung atau tidak langsung, yang mengenai sistem muskuloskeletal dan semua sistem atau organ lain yang memengaruhinya sehingga menimbulkan gangguan fungsi sistem tersebut.

Dari pemaparan di atas maka peneliti akan melaksanakan program pengabdian kepada masyarakat untuk meningkatkan ilmu dan pengetahuan mengenai penanganan cedera. Kegiatan ini diharapkan dapat membantu kegiatan serta proses ekstrakurikuler di sekolah tersebut.

\section{METODE PELAKSANAAN \\ Tempat dan Waktu}

Pelaksanaan pelatihan penangangan cedera dilakukan di Aula dan kelas Sekolah SMAN 1 Pringsewu yang terletak di JL. Olahraga No.01 Kecamatan Pringsewu Barat, Kabupaten Pringsewu, Provinsi Lampung. Kegiatan ini dimulai dari bulan Oktober - November tahun 2020.

\section{Khalayak Sasaran}

Sasaran dalam kegiatan pelatihan ini adalah siswa anggota ekstrakurikuler olahraga di SMAN 1 Pringsewu. Jumlah keseluruhan dari anggota eksul olahraga yakni 63 Siswa, yang terdiri dari eksul Basket, Futsal, Taekwondo,dan Karate.

\section{Metode Pengabdian}

Dalam kegiatan Pengabdian Kepada Masyarakat ini ditawarkan berbagai pendekatan. Metode pendekatan yang dilakukan dalam pelatihan penangan cidera olahraga adalah sebagai berikut:

1). Menggunakan Ceramah meyampaikan materi-materi pendukung cedera massage

2). Diskusi langsung dengan siswa anggota eksul tentang pengetahuan awal mereka terhadap cedera olahraga.

3). Pelatihan serta pembekalan pengetahuan baik secara teori dan praktek

4). demontrasi dan praktek teknik manipulasi massage. 


\section{HASIL DAN PEMBAHASAN}

Massage cedera merupakan suatu teknik pemijatan atau pengurutan yang dilakukan tujuan guna memulihkan anggota tubuh seorang yang mengalami cedera saat berolahraga(Hilmainur Syampurma, 2020) . Menurut Bambang Wijanarko (2010)masase terapi cedera olahraga hanya menggunakan beberapa teknik berikut, yaitu "gerusan (friction) dan gosokan (effleurage) menggunakan ibu jari, dan dilanjutkan dengan penarikan (traksi) untuk mengembalikan sendi pada posisinya (reposisi)."

Berdasarkan teori-teori yang telah dijelaskan, bahwasanya pemberian/penanganan dengan memberikan pelayanan/jasa cedera massage pada saat ini sangat dibutuhkan sekali. Karena latihan yang berat dan kurangnya pemanasan dapat menyebabkan terjadinya cidera. Dengan adanya pelatihan cedera massage ini, telah memberikan pengetahuan dan keterampilan kepada peserta pelatihan. Sehingga para peserta mengetahui ilmuilmu tentang cedera massage. Dengan mengetahui teori yang ada tentang cedera,jenis-jenis dan bentuk penangannannya, akan meminimalisir terjadinya keselahan. Selain itu dengan adanya pelatihan, memberikan informasi yang jelas tentang waktu-waktu yang tepat untuk pemberian pelayanan/jasa massage. Dengan pelatihan yang telah dilaksanakan ini telah membawa dampak positif kepada seluruh pesesrta. Mulai dari terciptanya lapangan kerja baru, memberikan tambahan ekonomi, dan memberikan kesempatan kepada peserta untuk mendedikasikan ilmu yang telah didapat ke lapangan dan masyarakat.

\section{KESIMPULAN}

Beberapa hal yang dapat disimpulkan dari kegiatan penerapan praktikum keterampilan masasge, sebagai tambahan Pengetahuan mahasiswa bertambah dalam menerapkan keterampilan masasge kepada masyarakat luas. Untuk Siswa menambah pengetahuan tentang terapi masase olahraga baik secara teori maupun praktek agar dapat diterapkan oleh siswa sebagai salah upaya peningkatan prestasi dalam bidang olahraga. Dan tentunya para peserta pelatihan mendapatkan pengetahuan yang lebih mendalam mengenai cedera olahraga. Pengetahuan yang diperoleh tidak hanya dalam penjelasan materi dan teori saja tetapi juga melakukan praktek langsung diharapkan nantinya dapat mencegah dan meminimalisir terjadinya cedera yang terjadi di lapangan baik saat latihan maupun kejuaraan.

\section{UCAPAN TERIMA KASIH}

Ucapan terimakasih kami sampaikan kepada Universitas Teknokrat Indonesia yang telah memberikan hibah Pengabdian Kepada Masyarakat (PKM) tahun pelaksanaan 2020. Kami ucapkan terima kasih juga kepada Kepala Sekolah SMAN 1 Pringsewu yang telah memberikan kesempatan kepada kami untuk melaksanakan kegiatan pengabdian masyarakat.

\section{REFERENSI/DAFTAR PUSTAKA}

Fondy, Tommy. (2012). Merawat dan Mereposisi Cedera Tubuh. Jakarta.

Komariya, M.Pd. Dra. Lilis. (2010).Modul Pencegahan dan Perawatan Olahraga.

Riyadi,Slamet, dkk. (2010). Massage Terapi Cidera Olahraga.Yuma Pustaka.

Wijanarko, Bambang, dkk. (2010). MassageTerapi Cedera Olahraga. Surakarta: Yuma Perkasa.

Syampurma, Hilmainur. (2020). Pelatihan Cedera Massage Nasional Tingkat 1. Journal Berkarya Pengabdian kepada Masyarakat 2(1), 39-38 


\section{BIOGRAFI PENULIS}

\begin{tabular}{|l|l|}
\hline & $\begin{array}{l}\text { Nama : Eko Bagus Fahrizqi, M.Pd } \\
\text { TTL. : Gedong Tataan, 17 Agustus 1991 } \\
\text { Pendidikan : Universitas Lampung (S1)/Universitas negeri Jakarta (S2) }\end{array}$ \\
\hline$:$ & $\begin{array}{l}\text { Rachmi Marsheilla Agus, M.Pd. } \\
\text { Pendidikan : Universitas Lampung (S1)/Universitas Negeri Semarang (S2) }\end{array}$ \\
\hline & $\begin{array}{l}\text { Rizki Yuliandra, M.Pd. } \\
\text { Pendidikan : Universitas Lampung (S1)/Universitas negeri Jakarta (S2 }\end{array}$ \\
\hline
\end{tabular}

